\title{
IMPACTOS AMBIENTAIS DA PRODUÇÃO VEGETAL NO PROCESSO DE DESERTIFICAÇÃO DO SEMIÁRIDO ALAGOANO: O CASO DE OURO BRANCO - AL
}

\author{
Sheylla Patrícia Gomes do Nascimento², João Manoel da Silva1, Edilsa Oliveira dos Santos $\underline{2}$, Poliana \\ Virgílio Mendes da Silva ${ }^{3}$, James Rafael Ulisses dos Santos ${ }^{5}$, Tania Marta Carvalho dos Santos ${ }^{4}$
}

\author{
'Eng. Agrônomo, Doutorando Rede Nordeste de Biotecnologia, Universidade Federal de Alagoas, Maceió, Brasil. E-mail: jm.agro@ \\ hotmail.com. \\ ${ }^{2}$ Mestre em Geografia, PPG-Geografia, Universidade Federal de Sergipe, São Cristóvão, Sergipe, Brasil. E-mail: edilsakit@hotmail. \\ com, sheyllapatricianascimento@gmail.com. \\ ${ }^{3}$ Geógrafa, Prefeitura Municipal de Ouro Branco, Alagoas, Brasil. E-mail: poli.v.silva@hotmail.com. \\ ${ }^{4}$ Profa Dra, Centro de Ciências Agrárias, Universidade Federal de Alagoas, Rio Largo, Brasil. E-mail: tmcs@ceca.ufal.br. \\ ${ }^{5}$ Universidade Federal do Espírito Santo, PPG-Geografia, Vitória-ES, Brasil. E-mail: jamesrulisses@gmail.com.
}

\begin{abstract}
RESUMO: O objetivo deste trabalho é analisar os impactos ambientais negativos do processo de desertificação em regiões semiáridas, e como estes afetam a produção vegetal no município de Ouro Branco/Alagoas. 0 município localiza-se na região semiárida alagoana, que integra o domínio da Caatinga, dentro da região conhecida como Polígono das Secas, compreendendo a porção oeste do Estado. A desertificação, devido ao seu estágio elevado, ocasionada por fatores naturais e antrópicos vem transformando a paisagem e comprometendo o solo, desencadeando assim, a baixa no plantio e cultivo de algumas culturas comuns na região como, palma forrageira, milho, feijão, macaxeira entre outros, deixando os produtores locais sem alternativas para a prática agrícola. Como procedimentos metodológicos foram realizadas etapas de leituras bibliográficas, coletas e análises de informações, trabalho de campo com registros fotográficos, demarcação das áreas através de suas coordenadas geográficas com receptor GPS Garmim Etrex 30. Através destas informações aferidas em gabinete e campo foi possível evidenciar os impactos ambientais originários deste processo, e a confecção do produto cartográfico da área identificando principal ponto de desertificação no município, posto nesta pesquisa. Por meio das análises cartográficas e paisagísticas observou-se degradação ambiental dos seus recursos naturais, o que desfavorece 0 desenvolvimento agrícola e social.
\end{abstract}

Palavras-chave: Semiárido, desenvolvimento agrícola, degradação do solo, ação antrópica

\section{ENVIRONMENTAL IMPACTS OF VEGETAL PRODUCTION ON THE DESERTIFICATION PROCESS OF ALAGOAN SEMI ARID: THE CASE OF OURO BRANCO - AL}

\begin{abstract}
The objective of this work is to analyze the negative environmental impacts of the desertification process in semi arid regions, and how these affect the vegetal production in the municipality of Ouro Branco/ Alagoas. The municipality is located in the Alagoan semi arid region, which is part of the Caatinga domain, within the region known as Polígono das Secas, comprising the western portion of the State. Desertification, due to its high stage, caused by natural and anthropogenic factors, has been transforming the landscape and compromising the soil, thus triggering the decline in the planting and cultivation of some common crops in the region, such as forage palm, maize, beans, others, leaving the local producers without alternatives to the agricultural practice. As methodological procedures, bibliographic readings, collection and analysis of information, field work with photographic records, and demarcation of the areas through their geographical coordinates with Garmim Etrex 30 GPS receiver were carried out. environmental impacts originating from this process, and the making of the cartographic product of the area identifying the main point of desertification in the municipality, put in this research. Through the cartographic and landscape analysis environmental degradation of its natural resources was observed, which undermines agricultural and social development.
\end{abstract}

Keywords: Semi arid, agricultural development, soil degradation, antropogenic action 


\section{INTRODUÇÃO}

A desertificação é um processo que transforma solos férteis em desertos, modifica a paisagem local e interfere no sistema dinâmico dos condicionantes físicos - naturais do meio, além de atingir a sociedade local, podendo ocorrer de forma natural ou por ação antrópica. Tal processo é evidenciado, principalmente em regiões áridas e semiáridas, onde dispõem em seu regime pluviométrico de precipitações anuais baixas e bastante variáveis, seja no espaço quanto no tempo, com evapotranspirações altas e temperaturas elevadas, o que caracterizam a região.

As combinações destes fatores associados à desertificação têm causado impactos negativos e de alto risco ao desenvolvimento da agricultura nestas áreas. Decorre então, em função do desmatamento da vegetação nativa, exemplo, a Caatinga, perca de nutrientes empobrecendo o solo, uso de fertilizantes, processos erosivos atenuantes, acidificação, salinização e compactação dos solos, acarretando, portanto, na baixa produtividade vegetal, como o cultivo da palma forrageira (Opuntia cochenillifera), entre outras culturas.

Além da contínua degradação ambiental, que se apresenta muitas vezes lenta e disfarçada, porém gradual, devido a exploração e manejo inadequado dos recursos naturais, em especial no sertão nordestino brasileiro, como o caso do município de Ouro Branco, que compõe o semiárido alagoano. Estudos realizados pelo Programa das Nações Unidas para o Meio Ambiente - PNUMA estima que as taxas anuais de desertificação cheguem em torno de 21 milhões de hectares por ano sendo um agravante nas zonas de aridez e semiaridez no mundo (GUERRA; JORGE, 2014).

\section{MATERIAL E MÉTODOS}

O trabalho contemplou como procedimentos metodológicos leituras acerca da temática e trabalhos de campo com determinação das coordenadas geográficas e UTM pelo uso do receptor Global Positioning System (GPS) da marca Garmin, modelo Etrex 30 e obtenção de todas as informações passíveis de serem coletadas através de uma visita técnica, além de registros fotográficos com câmera Canon SX 500 aferindo as informações in locu sobre a redução da produção vegetal.

Os dados coletados foram sistematicamente analisados, e com isso alimentarem um banco de dados. Esses dados possibilitaram a elaboração de um mapa de localização e outro destacando dois pontos de desertificação em estágio avançado um sendo na zona urbana da cidade e outro na zona rural, precisamente no Povoado Capelinha.

Com isso as informações são complementadas nesta pesquisa. Na elaboração dos mapas, utilizou-se como base cartográfica o mapa municipal estatístico em formato digital do IBGE (Censo 2010), e a base cartográfica do Estado de Alagoas, disponibilizada pelo Instituto de Meio Ambiente - IMA (2015), e os pontos coletados em campo.

O município de Ouro Branco está localizado na região Noroeste - NW do estado de Alagoas, limitandose a norte e a leste com o estado de Pernambuco, a Sul com o município de Maravilha e a Oeste com Canapi. A área da unidade territorial corresponde 204,771 km2 (IBGE, 2010), inserida na mesorregião do Sertão Alagoano e na microrregião de Santana do Ipanema (Figura 1). 
Figura 1.Mapa da Área de Estudo, município de Ouro Branco - Sertão alagoano. Fonte: IBGE (2010); IMA (2015). Elaboração: Autores (2018).

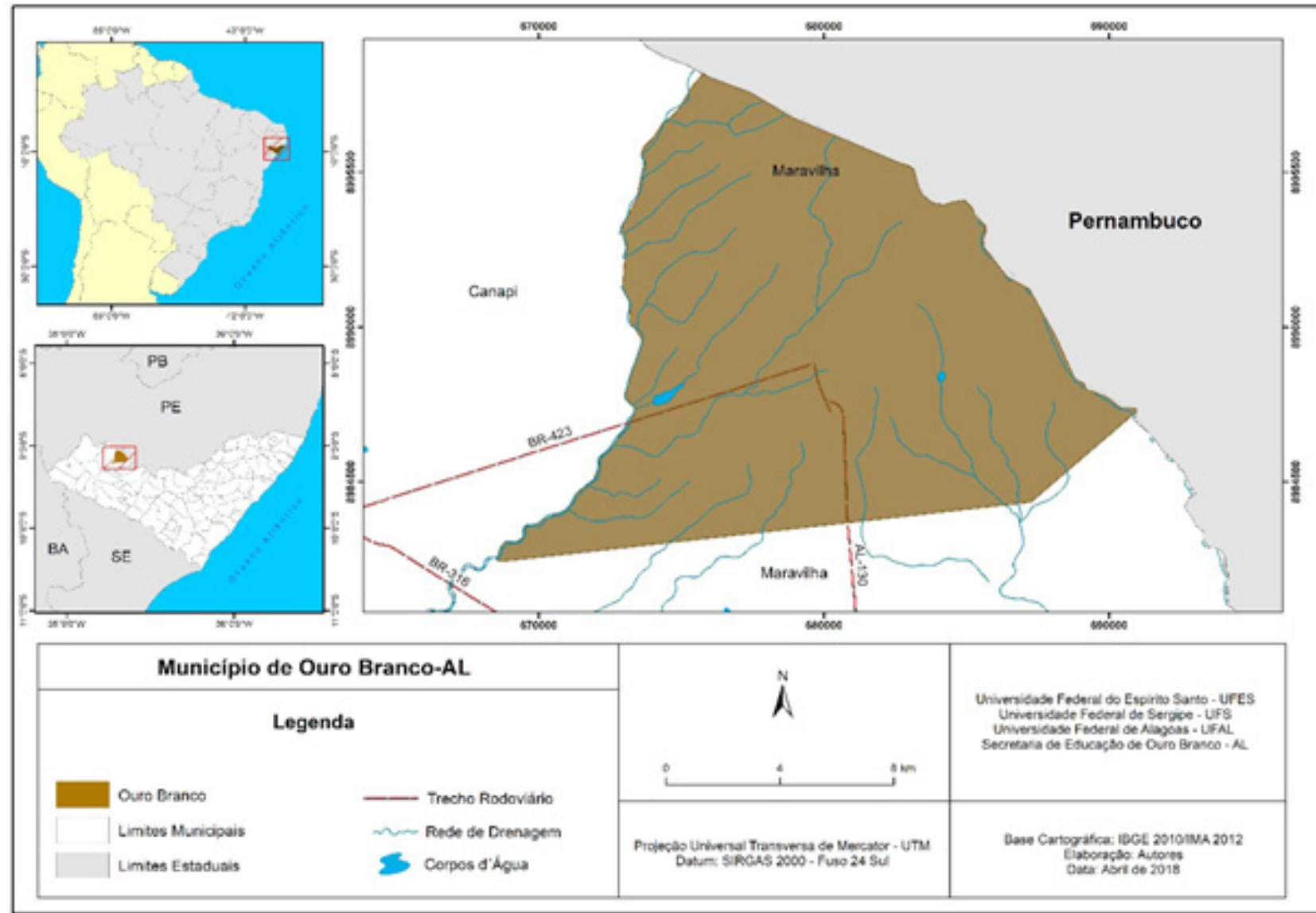

Nesses pontos foi possível identificar alguns fatores determinantes à caracterização de impactos ambientais e degradação das terras na área de estudo, por meio da desertificação e como este processo acarreta na diminuição das atividades agrícolas.

\section{RESULTADOS E DISCUSSÃO}

A região semiárida de Alagoas, na parte que compreende a parcela inserida do município de Ouro Branco desenvolveu-se através de atividades agropecuárias, no seu processo de interiorização e no cultivo de algodão, daí o nome da cidade por conta das extensas fazendas de algodão, entre outras culturas como a palma forrageira (0. cochenillifera), como alimentação do gado, já que a pecuária era intensa nestas áreas.

Ao longo dos anos devido às irregularidades pluviométricas típicas da região, e a intensa ação antrópica sobre os recursos naturais com 0 desmatamento da Caatinga, a compactação dos solos, pelo pisoteio dos ruminantes, a exemplo, fertilização das terras, por meio de usos de corretivos agrícolas, pois os solos são rasos, e poucos férteis, provocaram então a perda de nutrientes, que por sua vez foram acidificando e salinizando os solos, desencadeando um processo gradual de desertificação presente na área em questão e com isso comprometendo a produção vegetal deixando as plantas expostas aos estresses numa relação desigual entre sociedade e natureza, bem como as interações solo-planta-atmosfera.

A partir desta análise foi possível identificar dois pontos visíveis de desertificação no município, um na área urbana e outro na zona rural, no Povoado Capelinha, onde as comunidades locais tem todo seu cultivo vegetal comprometido pelos avanços da desertificação no semiárido alagoano (Figura 2). 
Figura 2. Pontos de desertificação elevada no munícipio de Ouro Branco - AL. Fonte: IBGE (2010), IMA (2015); Trabalho de Campo (2018). Fonte: Autores (2018).

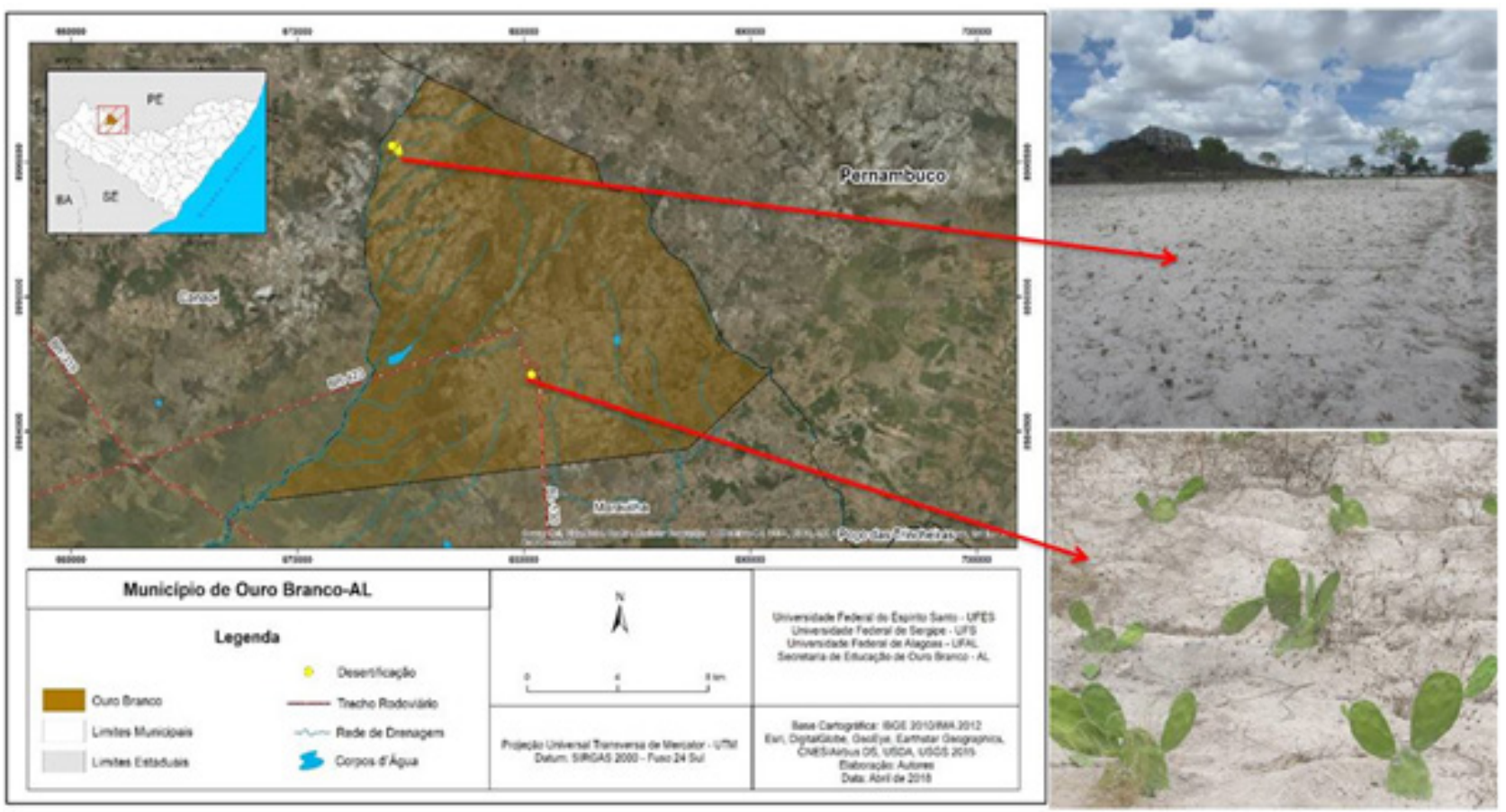

Os impactos ambientais analisados e solos no processo de desertificação estão dispostos na evidenciados em campo, por conta da degradação dos Tabela 1, adaptada conforme Guerra e Jorge (2014).

Tabela 1. Classificação dos fatores de degradação das terras (FAO, 1980 apud GUERRA; JORGE, 2014).

\begin{tabular}{lll}
\hline & Ações antrópicas & Condições naturais \\
\hline & Desmatamento & Topografia \\
& Superpastoreio & Textura do solo \\
Fatores facilitadores & Uso excessivo da vegetação & Composição do solo \\
& Taludes de corte & Cobertura vegetal \\
& Remoção de cobertura vegetal para cultivo & Regime hidrológico \\
\hline \multirow{5}{*}{ Fatores diretos } & Uso de máquinas & Chuvas fortes \\
& Condução de gado & Alagamentos fortes \\
& Encurtamento do pousio & Ventos fortes \\
& Entrada excessiva de água e/ou drenagem insuficiente & \\
& Uso excessivo de produtos químicos/estrume & \\
& Disposição de resíduos domésticos/industriais & \\
\hline
\end{tabular}

Nesse aspecto, considera-se que a recuperação de áreas degradadas, como o caso de ouro Branco, necessita de práticas conservacionistas, como exposto por Nascimento et al. (2017). Além dos impactos antrópicos observados na área, também se considera os caracteres físicos do solo, como a pedregosidade, 0 solo tipicamente arenoso e de baixa fertilidade natural.

\section{CONCLUSÕES}

Por meio da análise das imagens e dos fatores determinantes para 0 processo de desertificação da área de estudo, entende-se que esse processo é ocasionado tanto por ações antrópicas, como as más práticas agrícolas adotados na região, bem como condições naturais como tipo/classificação e profundidade do solo.

\section{AGRADECIMENTOS}

Prefeitura Municipal pelo apoio na condução das avaliações in locu. 


\section{REFERÊNCIAS}

ALAGOAS. Instituto de Meio Ambiente do Estado de Alagoas - IMA/AL. Base cartográfica de Alagoas.

Maceió: Dados vetoriais e matriciais, 2015. Disponível em: <http://www.ima.al.gov.br/servicos/downloads/> Acesso em: 03 de abril de 2018.

BRASIL. Instituto Brasileiro de Geografia e Estatística - IBGE. Município de Ouro Branco - Alagoas. Rio de Janeiro: Censo municipal 2010. Disponível em: <https:// cens02010.ibge.gov.br/> Acesso em: 04 de abril de 2018.
GUERRA, J.T.; JORGE, M.C.O. Degradação dos solos no Brasil. 1. ed. - Rio de Janeiro: Bertrand Brasil, 2014. 320p.

NASCIMENTO, M. S.; CRISTO, C. C. N.; VALENTE, E. C. N.; LIMA, A. S. T. Capacidade de uso do solo do campus Maragogi. Encontro Regional de Agroecologia do Nordeste, 2017, 1, 1-6. 